\title{
RECURSOS DIGITAIS E APRENDIZAGEM DE INGLÊS COMO LÍNGUA ESTRANGEIRA
}

\section{DIGITAL RESOURCES AND THE LEARNING OF ENGLISH AS A FOREIGN LANGUAGE}

Celso Tumolo

Universidade Federal de Santa Catarina

\section{Resumo}

Apresento, neste artigo, o resultado de uma pesquisa sobre quais recursos digitais podem auxiliar o desenvolvimento de inglês como língua estrangeira (LE), a partir de recursos disponibilizados na Internet, e faço uma caracterização dos recursos identificados. Considerando quatro aspectos essenciais para o desenvolvimento de uma LE, a saber, componentes da habilidade linguística, interação, integração das quatro habilidades, e motivação, apresento uma reflexão sobre como esse auxílio pode acontecer, apontando formas do uso de cada um para ensino/ aprendizagem de inglês como LE. For fim, concluo que o uso dos recursos digitais identificados possibilita satisfazer os aspectos essenciais, tanto para o professor em sua prática docente, como para um aprendiz autônomo, com o objetivo do desenvolvimento de inglês como LE.

\begin{tabular}{|l|l|l|l|l|}
\hline Ilha do Desterro & Florianópolis & n 66 & p. 203- 238 & jan/jun 2014 \\
\hline
\end{tabular}


204 Celso Tumolo, Recursos digitais e aprendizagem de inglês...

Palavras-chave: recursos digitais; língua estrangeira; ensino; aprendizagem.

\begin{abstract}
In this article, I present the results of a research carried out on the digital resources used for the development of English as a foreign language (FL), based on the resources available on the Internet, as well as a characterization of the identified resources. Considering four essential aspects for the development of a foreign language, namely components of language ability, interaction, integration of the four skills, and motivation, I present a reflection on how they can be used, pointing to ways each of the resources identified can be used for the teaching and learning of English as a FL. Lastly, I conclude that the identified resources can meet the requirements of the essential aspects, both for the teacher to use in the teaching practice, and for the learner, with autonomous initiatives for learning, with the aim of developing English as a FL.
\end{abstract}

Keywords: digital resources; foreign language; teaching; learning.

Tecnologia sempre esteve presente em processos de ensino e aprendizagem de língua estrangeira $(\mathrm{LE})^{1}$. Recursos tecnológicos como o giz, o quadro branco, o gravador, o projetor de slides, o retroprojetor, o CD e o DVD e, mais atualmente, os recursos digitais ${ }^{2}$, têm contribuído para auxiliar no desenvolvimento de uma LE.

Neste artigo, apresento o resultado de uma pesquisa sobre quais recursos digitais podem auxiliar o desenvolvimento de inglês como língua estrangeira (LE), a partir de recursos disponibilizados na Internet, e uma reflexão sobre como esse auxílio pode acontecer. Para isto, primeiramente, trato de quatro aspectos considerados essenciais para o desenvolvimento de uma LE, que podem ser focados pelos recursos: componentes da habilidade linguística, interação, integra- 
ção das quatro habilidades, e motivação. Em seguida, apresento uma caracterização dos recursos identificados, com menções ao seu uso para ensino/aprendizagem de inglês como LE.

\section{Aspectos essenciais focados pelos recursos digitais}

Apresento, nesta seção quatro aspectos essenciais para o desenvolvimento de uma LE que podem ser focados, individualmente ou em alguma forma de combinação, pelos recursos digitais: componentes da habilidade linguística, interação, integração das quatro habilidades, e motivação.

\section{Componentes da habilidade linguística}

O uso de uma língua em situações de comunicação requer o domínio de seus componentes essenciais. Bachman (1990) e Bachman e Palmer (1996) discutem o que consideram ser os principais componentes da habilidade linguística: conhecimento linguístico conhecimento organizacional e conhecimento pragmático, e competência estratégica.

Conhecimento organizacional envolve o domínio do reconhecimento e da produção de sentenças gramaticalmente corretas, como também a compreensão de seu conteúdo proposicional. Assim, baseia-se no conhecimento de vocabulário, morfologia, sintaxe e fonologia, como também de conhecimento de coesão e de organização retórica.

Conhecimento pragmático refere-se à habilidade de relacionar enunciados ou sentenças e textos ao seu significado no seu contexto e às intenções dos usuários. Dessa maneira, baseia-se no conhecimento da língua para exercer funções ideacionais, como uso da língua 
para expressar ou compreender ideias, conhecimento ou sentimento; funções manipulativas, como pedir, sugerir, controlar, avisar; funções heurísticas, como possibilitar ensino e aprendizagem; e funções imaginativas, como para propósitos de humor ou poesia. Baseia-se também no conhecimento de dialetos, registros, referências culturais e figuras de linguagem.

A competência estratégica é responsável por implementar os componentes do conhecimento linguístico ao uso da língua em contexto comunicativo, assim relacionando os conhecimentos linguísticos ao contexto da situação. Para Bachman (1990), as estratégias metacognitivas, principais da competência estratégica, possibilitam, ao usuário da língua, a habilidade ou capacidade de criar e interpretar discurso em situações de uso.

Assim, considerando a relevância do conhecimento linguístico e da competência estratégica para o uso comunicativo de língua estrangeira, como defendido por Bachman (1990) e Bachman e Palmer (1996), o desenvolvimento de cada um passa a ser essencial, e situações de aprendizagem devem contemplá-los.

\section{Interação}

O desenvolvimento de uma língua exige contato, o qual pode ser estabelecido de pelo menos duas formas de interação: interação aprendiz-conteúdo e interação aprendiz-proficiente (falante/interlocutor com maior conhecimento linguístico da língua-alvo $)^{3}$.

A interação aprendiz-conteúdo pode ocorrer via interação com conteúdo informativo ou conteúdo linguístico. No caso da interação com conteúdo informativo, o aprendiz pode, de forma autônoma, fazer uso de sua capacidade de auto-avaliação e selecionar o conteúdo a ser por ele usado, com insumo linguístico adequado 
ao seu nível de compreensão, como também buscar suas estratégias de aprendizagem, em particular as estratégias metacognitivas, como o monitoramento da aprendizagem, para fazer o melhor uso do material disponível ${ }^{4}$.

No caso da interação com conteúdo linguístico, disponibilizado para a aprendizagem da língua-alvo, o aprendiz pode buscar atividades apresentadas na forma de atividades digitais. Essas atividades possibilitam respostas automáticas, com feedback customizado, ou seja, com comentários sobre o desempenho de cada aprendiz, seus acertos e seus erros, com explicações para ambos.

O recurso de feedback (avaliativo ${ }^{5}$ ) automático, com foco na performance do aprendiz, baseia-se em um mecanismo de comparação da resposta dada com uma lista predeterminada de palavras, funcionando bem com atividades de preenchimento de lacunas, de verdadeiro ou falso, ou de múltiplas escolhas. Recursos como este estão sendo chamados de CALL tutors (AMARAL, 2011). Há, mais recentemente, recursos que usam mecanismos para além da simples comparação com uma lista predeterminada, que fazem uso de sistemas que conseguem diagnosticar erro e que geram feedback individualizado para o aprendiz, recursos estes que são chamados IntelligentCALL (ICALL), ou Intelligent Language Tutoring Systems (ILTS) (AMARAL, 2011) e, desta forma, focando no que o aprendiz sabe e no que ele precisa aprender. Isso permite ao aprendiz maior controle sobre o desenvolvimento de sua aprendizagem.

O outro caso de interação, a interação aprendiz-proficiente, pode ocorrer via comunicação com falantes da língua-alvo com maior conhecimento linguístico. Interação tem sido considerada fundamental no processo de aquisição de LE. Aprendizes desenvolvem sua LE em interação com outros com maior proficiência, quer sejam nativos ou não, em um processo de negociação de significados. 
Esse tipo de interação permite satisfazer princípios essenciais do processo de aprendizagem de uma LE, como apontados por várias hipóteses propostas para a explicação do processo de desenvolvimento de uma LE.

Krashen (1982) propôs a Hipótese do Insumo Compreensível (Comprehensible Input Hypothesis), a qual sugere como insumo linguístico compreensível pode colaborar com o desenvolvimento de uma segunda língua. Swain (1985), por sua vez, propõe a Hipótese do Output Compreensível (Comprehensible Output Hypothesis). Para a autora, durante interações na língua-alvo, pode haver quebra na comunicação, e o aprendiz recebe insumo negativo, mostrando a ineficiência de sua produção. Por isso, o aprendiz passa a focar nas formas linguísticas para expressar o conteúdo desejado, assim testando hipóteses sobre a formação da língua, e tentando novas formas e/ou modificando outras para se expressar e ser compreendido. Esse processo auxilia, segundo a autora, o desenvolvimento da LE. Ainda sobre o desenvolvimento de LE, Schmidt (1990; 1995) propõe a Hipótese do Noticing (Noticing Hypothesis), que sugere que notar aspectos linguísticos pode ser fundamental para o processo de aprendizagem de uma LE, permitindo a conversão de input em intake.

Nesse debate, participa, também, Long (1985; 1996), com a Hipótese da Interação (Interaction Hypothesis), que sugere que, durante interações entre falantes (com maior conhecimento da língua alvo), um processo de negociação de significados, em que ocorre modificações linguísticas que permitem o provimento do insumo necessário para o aprendiz.

$\mathrm{Na}$ interação aprendiz-proficiente, feedback pode ter um papel fundamental, podendo ser mais explícito ou mais implícito. Feedback mais explícito contem sinalização explícita dos erros cometidos pelo aprendiz, levando-o ao reconhecimento e à correção. Feedback mais 
implícito, por outro lado, contém sinalização mais implícits sobre os erros cometidos, como silêncio, pedidos de esclarecimento, etc. No primeiro caso, há uma negociação de significados em que um dos interlocutores sinaliza, por meio de feedback negativo, que não houve compreensão, levando ao ajuste do outro; no segundo caso, o interlocutor mais proficiente nota o erro cometido e, em forma de recast $^{6}$, devolve a forma correta para o outro. Ambos os feedbacks podem levar o aprendiz a notar o problema, a lacuna de conhecimento linguístico, entender o ocorrido e buscar uma sistematização de um padrão linguístico.

\section{Integração das quatro habilidades}

O ensino de língua estrangeira tem sido, muitas vezes, caracterizado pela separação entre as quatro habilidades de compreensão oral (CO)(listening), expressão/produção oral (EO)(speaking), compreensão escrita (CE)(reading) e expressão/produção escrita (EE) (writing). No entanto, embora útil para o ensino de LE, a separação das habilidades é artificial, já que o uso autêntico da língua envolve integração. Assim, a competência comunicativa deve ser desenvolvida por meio da integração das habilidades.

Há abordagens para o desenvolvimento da competência comunicativa com base na integração das habilidades, como a abordagem por tarefas e abordagem por conteúdos (que engloba foco em temas). Pela abordagem por tarefas (task-based approach), o aprendiz pode desenvolver tarefas como escrever um artigo de revista, um pôster de cinema, produzir um vídeo com instruções, etc. O desenvolvimento de uma tarefa implica o trabalho colaborativo, com outros aprendizes, que requer comunicação na língua-alvo. Pela abordagem por conteúdo (content-based approach), o aprendiz é exposto a conteúdos como 
ecologia, ciências, conhecimento geral, e pode estabelecer comunicação, na língua-alvo, com seus pares sobre os temas trabalhados, desenvolvendo, assim, de forma integrada, as habilidades linguísticas.

Oxford (2001) enfatiza a importância da adoção dessas abordagens para o ensino de língua estrangeira, pois entende que integrar as habilidades tem as vantagens de a) expor o aprendiz à língua autêntica; b) permitir uma interação natural, envolvendo a complexidade do uso de língua para comunicação; c) promover a aprendizagem de conteúdo real; e d) permitir ao professor a avaliação do progresso dos alunos nas habilidades múltiplas, e) tornar a língua o meio real de interação e compartilhamento entre as pessoas; e f) motivar aprendizes de todas as idades e experiências.

\section{Motivação}

A contribuição da motivação para educação tem sido tema de debate e, certamente, avanços foram feitos na pesquisa e prática docente como resultado. Grosso modo, motivação está relacionada a 'motivo', a 'movimento' em direção a algo, supostamente objetivos desejados, envolvendo as razões para agir ou comportar de uma forma específica para alcançar os objetivos desejados.

Há muitos fatores envolvidos em motivação, como diferenças individuais, situacionais, fatores sociais, culturais e cognitivos, envolvendo áreas como psicologia social, cognitiva, educacional, para sua explicação. A neurociência nos mostra, atualmente, que há uma relação entre emoção, motivação e memorização. $O$ sistema límbico, conjunto de estruturas cerebrais, é responsável por funções como emoção, motivação e memória de longo prazo. Emoção e motivação estão relacionadas com a memorização de informações de longo prazo, e é possível afirmar que quanto mais emoção, maior motivação, 
maior a chance de armazenamento de informações na memória de longo prazo, essencial para a aprendizagem.

Em reflexão sobre as orientações de motivação, Ryan e Deci (2000, p. 54-55) mostram que as atitudes e objetivos que levam à ação do aprendiz podem ser distintos. Como dizem os autores,

um estudante pode estar altamente motivado a fazer tarefas por curiosidade ou interesse ou, alternativamente, porque busca a aprovação do professor [...] pode estar motivado a aprender novas habilidades porque ele ou ela entende a utilidade potencial ou valor, ou porque aprender as habilidades levará a boas notas e os privilégios que elas trazem.

Por meio dos exemplos acima, os autores apresentam a distinção entre os dois tipos de motivação que governam as ações dos seres humanos: motivação intrínseca e motivação extrínseca. Para eles, motivação intrínseca refere-se a fazer algo porque é inerentemente interessante ou agradável, e motivação extrínseca a algo que trará resultados externos. De fato, essa distinção básica tem sido usada para as motivações, sendo que a intrínseca sempre se refere a algo interno, inerente ao aprendiz, que lhe traz prazer, enquanto a extrínseca a algo externo, que lhe impõe ações.

$\mathrm{Na}$ área de ensino/aprendizagem de língua estrangeira, Gardner $(1985 ; 2005)$ tem contribuído para a discussão sobre o aporte da motivação. $\mathrm{O}$ autor define motivação para aprender línguas como uma "combinação de esforço e desejo para alcançar o objetivo de aprender a língua e atitudes favoráveis em relação à aprendizagem da língua" (GARDNER, 1985, p. 10). Em seu modelo, o autor apresenta dois tipos de motivação: integrativa, se referindo ao desejo de se comunicar ou integrar com falantes da língua alvo; e instrumental, refletindo razões mais funcionais para a aprendizagem da língua alvo. 
212 Celso Tumolo, Recursos digitais e aprendizagem de inglês...

Em suma, os aspectos apontados têm sido envolvidos em debates sobre ensino/aprendizagem de LE. Devem, portanto, ser considerados nas escolhas feitas referentes ao processo de ensino/aprendizagem de inglês como LE, de forma que um professor possa ter suas decisões informadas em suas práticas docentes, ou um aprendiz, de forma mais autônoma, ter suas decisões informadas em suas práticas de aprendizagem. Na próxima seção, apresento uma reflexão sobre como recursos digitais podem contribuir para o ensino/aprendizagem de uma LE.

\section{Recursos digitais: caracterização e uso para LE}

Apresento, nesta seção, alguns recursos digitais que podem envolver os aspectos essenciais para o desenvolvimento de uma LE: atividades educativas digitais, áudio livros, e-pals, infográficos, jogos eletrônicos, livros digitais, vídeo, e os recursos da Web 2.0.

\section{Atividades educativas digitais}

Vários tipos de atividades educativas digitais podem ser criados e usados para auxiliar no desenvolvimento das habilidades linguísticas em LE alvo7: 1) múltipla escolha; 2) preenchimento de lacunas; 3) palavras cruzadas; 4) criação de sentenças com palavras embaralhadas; e 5) combinar colunas.

Atividades de múltipla escolha envolvem o provimento de perguntas e de várias possíveis respostas, sendo uma correta e as outras incorretas. Podem servir para avaliar compreensão oral e escrita ${ }^{8}$, conhecimento linguístico (de vocabulário e de gramática) da língua alvo.

Atividades de preenchimento de lacunas são feitas a partir da extração de palavras de textos, de forma aleatória ou proposital, crian- 
do lacunas que devem ser preenchidas. Elas focam essencialmente em conhecimento de vocabulário (função semântica e sintática).

As atividades de palavras cruzadas exigem o provimento de palavras e, assim, podem ter o objetivo de focar no ensino de vocabulário, já que perguntas são feitas ou lacunas são criadas em sentenças isoladas, cujas respostas em termos de palavras devem ser adivinhadas e colocadas no quadro das palavras cruzadas, nos sentidos vertical e horizontal, conforme instruções.

Atividades para criar sentenças com palavras embaralhadas exigem o reordenamento de palavras apresentadas aleatoriamente para formar uma sentença. Elas focam em conhecimento da gramática e do vocabulário da língua, assim na relação semântico-sintática entre as palavras para compor uma sentença. Isto significa que o aprendiz precisa conhecer o vocabulário e, considerando a relação sintática, escolher seu significado, ou seja, o significado que cada palavra assume na sentença, à medida que decide a ordem e combina as palavras.

A atividade de combinar colunas tem o objetivo de estabelecer a relação entre itens presentes em duas colunas distintas. Uma coluna pode ter uma palavra da LE e a outra coluna pode uma figura ou uma definição correspondente. Assim, figuras podem ser combinadas com palavras, por exemplo, para aprender vocabulário.

Essas atividades têm sido usadas para ensino e aprendizagem de LE, sendo, agora, na versão digital. Elas possibilitam a aprendizagem de componentes da habilidade linguística, em particular o conhecimento organizacional, envolvendo conhecimentos de vocabulário, de gramática (sintaxe) e de coesão, tendo também o papel, para o professor e para o aprendiz, de diagnosticar fontes de dúvidas, indicando o que precisa ser revisto e ainda aprendido. Possibilitam, também, a criação de saliência para aspectos da LE, com atenção focada em suas funções semântica e sintática, o que está relacionada 
214 Celso Tumolo, Recursos digitais e aprendizagem de inglês...

com a Hipótese do Noticing, pois permite notar aspectos linguísticos importantes para o processo de aprendizagem de uma LE.

Por estarem na forma digital, essas atividades podem fornecer respostas automáticas, com feedback customizado, ou seja, com comentários sobre o desempenho de cada aprendiz, seus acertos e seus erros, com explicações para ambos e, desta forma, focando no que o aprendiz sabe e no que ele precisa aprender. Isso permite ao aprendiz oportunidades de uso da língua (mesmo que restrito às características da atividade), dando-lhe maior controle sobre o desenvolvimento de sua aprendizagem.

Além de usuário das atividades, cada aprendiz pode se tornar um autor, passando a ter um papel mais ativo. Com programas específicos ${ }^{9}$, por iniciativa própria ou por solicitação de um professor, o aprendiz pode desenvolver as atividades, o que requer pesquisa e elaboração para as decisões necessárias sobre a língua e sobre o conteúdo, e as atividades resultantes podem ser disponibilizadas em páginas da Internet, ou mesmo ambientes virtuais de aprendizagem. $\mathrm{O}$ processo de autoria pode ser motivador e, por isso, criar condições favoráveis para a aprendizagem.

\section{Áudio livros}

Áudio livros referem-se à versão oral de livros escritos, ou seja, à gravação de textos lidos em voz alta. Embora sejam usados mais para fins de lazer e entretenimento, eles podem ser usados para fins didáticos, pois possibilitam o aprendizado do conteúdo gravado, mesmo quando o aprendiz está desempenhando outras atividades. Eles permitem, ao aprendiz, ouvir várias vezes o conteúdo, o que é fundamental em práticas de aprendizagem, pois pode trazer à consciência o conteúdo linguístico, permitindo, ao aprendiz, notá-lo. 
Como permitem ao aprendiz ouvir o texto escrito, eles facilitam o desenvolvimento das habilidades de compreensão oral. Por isso, devem ser escolhidos considerando o insumo linguístico, que precisa ser adequado em termos de complexidade da gramática, como também de densidade lexical, isto é, da proporção entre as palavras que podem ser desconhecidas em relação às conhecidas, mantendo sempre a densidade baixa. Desta forma, podem ser eficazes na aprendizagem de vocabulário e gramática da língua-alvo.

Áudio livros podem ser produzidos, envolvendo aprendizes em desenvolvimento de tarefas. Assim, a habilidade de expressão oral é também desenvolvida. Neste processo, considerações sobre o público-alvo devem ser feitas, envolvendo decisões sobre o registro da língua, isto é, nível de formalidade, como também a informatividade, isto é, o equilíbrio entre a informação já conhecida e a informação nova por parte do público-alvo. Desta forma, o aprendiz pode desenvolver sua competência pragmática em LE.

\section{Comunidades de Aprendizagem PenPals e E-pals}

Comunidades de Aprendizagem PenPals e E-pals são comunidades, disponíveis na Internet, organizadas para criar e estabelecer contatos e trocas de mensagens entre pessoas ou grupos de pessoas, normalmente de diferentes nacionalidades. Elas permitem estabelecimento de interação entre os usuários membros, feita normalmente via trocas de mensagens na língua-alvo, com uso autêntico da língua, em que os interlocutores estão negociando significado, ou seja, buscando suas estratégias para se comunicarem efetivamente e, assim, desenvolvendo também a competência estratégica. Comunidades voltadas para estabelecer comunicação entre pessoas disponibilizam uma plataforma e listas de pessoas com seus interesses ${ }^{10}$. 
Há comunidades de aprendizagem específicas em que os membros de diversas comunidades linguísticas (de diversos países) participam das interações, e pretendem aprender a língua nativa do interlocutor. Neste caso, há uma troca de conhecimentos de língua, em que o usuário oferece o conhecimento de sua língua-mãe, e busca aprender alguma língua-alvo. O usuário tem, assim, o papel de ensinar, fornecendo feedback para lições feitas por outros, como também de aprender, recebendo feedback de conhecedores de sua língua-alvo. Desta forma, cada membro cria condições de aprendizagem de sua língua nativa ao outro, ao mesmo tempo em que aprende, do outro, sua língua nativa ${ }^{11}$.

\section{Infográficos}

Infográficos são conhecidos como representações visuais gráficas de informação, dados e conhecimento, e são comumente planejados em três partes: a visual, que se refere às cores, aos ícones e aos gráficos; o conteúdo, que inclui texto, estatística e referências; conhecimento, que se refere aos fatos e conclusões intencionados. Possibilitam a representação visual de conceitos muitas vezes complexos de compreensão, e permitem ao leitor juntar os elementos para melhor compreensão.

Como infográficos envolvem representações visuais, eles tendem a ser bastante efetivos para o objetivo da comunicação, não somente porque são elementos adicionais para o processo de compreensão, mas também porque atendem a aprendizes que têm estilo mais visual de aprendizagem.

Lanlow, Ritchie e Crooks (2012) mostram três importantes benefícios do uso de infográficos: apelo visual, compreensão e retenção. Sobre o apelo visual, os autores mostram que, em um mundo 
com muita informação, destaques são importantes, focando em apelo visual, para atrair audiência.

Sobre compreensão, os autores afirmam que grande parte da informação apresentada atualmente em nossa sociedade está na forma visual. Ademais, o cérebro humano processa informação visual rapida e precisamente, sem muito esforço cognitivo de nossa atenção, e o tempo usado para compreensão é reduzido. E enfatizam que, como tanto imagens como palavras têm seu papel no processo de comunicação, de forma individual e complementar, o infográfico passa a ser um recurso eficaz, pois faz uso dos dois, sendo um aliado para a compreensão desejada.

Sobre o processo de retenção das informações, apresentadas com apelo visual, os autores fazem referência aos vários tipos de memória envolvidos no processo de compreensão, neste caso envolvendo compreensão de imagens também, em particular, o funcionamento e contribuição do que chamaram de memória de trabalho visual para a retenção da informação compreendida. Baseados em pesquisa, os autores afirmam que uma abordagem mais ilustrativa, com imagens, pode realmente auxiliar no processo de retenção das informações apresentadas.

Os autores enfatizam, no entanto, que as ilustrações devem complementar os outros elementos, mas sem causar distrações desnecessárias a ponto de prejudicar a representação da informação da forma mais adequada. Assim, deve haver uma adequação entre os elementos visuais e escritos, e que essa adequação deve estar de acordo com os objetivos do infográfico.

Os infográficos podem ser estáticos, interativos, ou animados. O infográfico estático ${ }^{12}$ apresenta as informações em forma de textos e imagens. O infográfico interativo ${ }^{13}$ permite alguma forma de interação, ou seja, a participação do usuário. O infográfico animado, ou vídeo infográfico ${ }^{14}$, traz as informações na forma de texto e imagens, 
mas com movimento, podendo ser acompanhado de uma narrativa e/ou música de fundo. O movimento permite que o conteúdo informativo seja apresentado de forma atraente, como também de forma contínua, como em fluxo, facilitando sua compreensão.

Com seus benefícios do apelo visual, compreensão e retenção, infográficos podem ter papel importante no processo de ensino/ aprendizagem de uma LE. Seu apelo visual auxilia a atrair a atenção, com suas múltiplas linguagens, incluindo diversidade de modalidades, de cores e formas.

Com a diversidade de modalidades, isto é, textos, imagens e som, a compreensão da informação desejada é facilitada para todos, atendendo aos diferentes estilos de aprendizagem. E como resultado, a retenção da informação pode ser aumentada. Assim, o conhecimento organizacional é desenvolvido, com insumo linguístico na forma do vocabulário e gramática da língua alvo, como também na forma de organização retórica de um gênero textual, que se caracteriza com multimodal ${ }^{15}$.

Infográficos podem ser usados para o ensino/aprendizagem da LE alvo, focando em alguns conhecimentos específicos, escolhidos para serem aprendidos ${ }^{16}$. Contudo, considerando a abordagem por conteúdo, especificamente a abordagem por temas, qualquer tema desenvolvido na língua-alvo no infográfico pode ser fonte de insumo linguístico para o ensino/aprendizagem da língua.

Infográficos podem ser produzidos, também, tornando-se uma tarefa a ser desenvolvida por aprendizes, seguindo a abordagem por tarefas. Assim, idealmente, o processo de desenvolvimento de um infográfico seria conduzido na língua-alvo, com a interação entre os aprendizes em situação autêntica de uso de língua, com um objetivo autêntico de produzir um infográfico na LE alvo. 


\section{Jogos Eletrônicos}

Jogos evoluíram com as inovações tecnológicas, acompanhando o surgimento e estabelecimento do televisor, do computador, e o advento da Internet e as plataformas virtuais, passando a ser chamados de jogos eletrônicos ou videogames e jogos online.

Grosso modo, os jogos eletrônicos/online podem ter as seguintes características: a) apresentam informações de forma auditória, visual e textual, constituindo uma variedade de insumo informativo; b) permitem a identificação com personagens, e mesmo a criação de avatares, com simulação de ações e de relações sociais e com experimentação; c) envolvem fantasias; d) são interativos (permitindo interação e interatividade); e) têm objetivos claros, e normalmente de curto prazo; f) têm desafios; g) têm conflitos; h) têm regras; i) envolvem resolução de problemas; j) são adaptativos: níveis adaptáveis e crescentes de dificuldade, progressivamente adaptado ao nível do jogador; k) têm mecanismo de recompensa contínua e gradual; el) têm mecanismo de feedback, inteligente, atendendo individualmente o aprendiz.

Jogos podem ser usados para fins didáticos, independente de serem originalmente criados para esse fim ${ }^{17}$. Em geral, todos eles envolvem alguma aprendizagem, tendo sempre alguma situação constituída como problema, que precisa ser resolvida como resultado da ação do jogador. Jogos educativos, por outro lado, pretendem auxiliar na construção de algum conhecimento e/ou desenvolvimento de alguma habilidade, específicos como programados. Eles são feitos para aprender conteúdos, expandir conceitos e desenvolver habilidades.

Em geral, os jogos educativos têm um papel lúdico, que estimula a motivação dos aprendizes que, por sua vez, é um fator determinante para qualquer aprendizagem, auxiliando na formação de memória de longo prazo ${ }^{18}$. Assim, os conhecimentos de vocabulário e gramáti- 
ca se beneficiam da memorização resultando da motivação inerente ao lúdico dos jogos.

Gee (2005) fala de 16 princípios de aprendizagem que jogos eletrônicos incorporam. São eles:

- $\quad$ identidade, pela qual os jogadores vivem e aprendem de forma compromissada com a nova identidade;

- $\quad$ interação, pois os jogos reagem às ações do jogador, com feedback e novos problemas;

- $\quad$ produção, pois os jogadores, além de receberem informações, também as produzem, não somente verbalmente, mas na constituição do jogo na medida em que tomam ações e decisões que modificam o jogo;

- espaço de risco, permitindo tomadas de risco, com a possibilidade de sucesso, mas também de fracasso, com a retomada a partir dele;

- customização, com a adequação do jogo ao estilo de aprendizagem e ao nível desejado;

- $\quad$ iniciativa, com um sentido de controle das ações;

- $\quad$ problemas ordenados, em que problemas anteriores permitem levantamento de hipóteses para resolver problemas posteriores mais complexos; 
- desafio e consolidação, com séries de problemas desafiadores e soluções, até a automatização das soluções, e integração do novo aprendizado com o conhecimento anterior;

- 'just-in-time’ e 'on-demand', pois a informação necessária é dada no momento em que é necessária, e por solicitação do aprendiz;

- significado contextualizado, pois os significados palavras acompanham ações, imagens e diálogos relacionados, não apenas definições;

- desafiador e factível, com os problemas apresentando desafios dentro do nível do possível para cada jogador, sendo, assim, altamente motivador;

- pensamento em sistema, encorajando jogadores a considerar os fatos de forma integrada, não isolada;

- exploração, pensamento lateral e reflexão de objetivos, na medida em que incentiva a exploração minuciosa da situação e o pensamento lateral, não somente o linear, para repensar os objetivos posteriores necessários para a solução dos problemas;

- ferramentas inteligentes e conhecimento distribuído, pois o conhecimento necessário para resolver os problemas e tomar as decisões é distribuído entre os jogadores, ou mesmo entre o jogador e o personagem virtual; 
- equipes com funções integradas, com cada jogador dominando e contribuindo com sua especialidade para a resolução do problema de forma integrada, pela equipe;

- desempenho antes da competência, pois os jogadores podem jogar enquanto desenvolvem sua competência.

Prensky (2001) tem afirmado que o trabalho com jogos digitais permite o desenvolvimento de um conjunto de habilidades cognitivas envolvendo representações tridimensionais do espaço, habilidades visual-espacial multidimensional, mapas mentais, descoberta indutiva (com observações, formulações de hipóteses e descoberta de regras), uso de atenção focada, e resposta mais rápida a estímulos esperados e não esperados. Por conta das diferenças, o autor afirma que a nova geração, de nativos digitais, tem um funcionamento mental diferente, desenvolvendo mentes hipertextuais, com estruturas cognitivas paralelas, não sequenciais.

Prensky (2002) afirma que jogar jogos é relaxante, motivador, e desafiante, ao mesmo tempo. É relaxante, pois envolve diversão no sentido do objetivo; é motivador e desafiante, pois mantém o jogador sempre em estado de desafio (físico, intelectual e emocional) no exato nível apropriado ao contexto e ao jogador, ajustando o jogo continuamente de forma a manter o jogador em uma 'zona de fluxo', com objetivos de curto prazo claros que o jogador, com esforço, consegue alcançar.

Assim, para fins educativos, jogos podem contribuir muito, com suas características, em especial, com seus objetivos claros, sistema de adequação ao nível do aprendiz, feedback imediato e inteligente, para fomentar a aprendizagem do jogador. 
Jogos podem ser usados para desenvolvimento da competência comunicativa em LE, focando, de forma individual e/ou integrada, nas quatro habilidades. Dependendo de suas características, eles envolvem leitura e/ou audição de regras e comandos, desenvolvendo as habilidades receptivas, ou mesmo a habilidade produtiva de escrita, quando informações são requisitadas.

Jogos possibilitam a interação entre jogadores na LE, podendo ser jogados, por exemplo, em redes sociais como o Facebook, com jogadores de várias nacionalidades. Desde o convite até mesmo o jogo todo, há interação na LE alvo. Por isso, há a negociação de significados essencial para a compreensão mútua antes do jogo, para as negociações iniciais e compreensão das regras, durante o jogo, a partir de suas demandas, e após o jogo, em que os jogadores trocam mensagens. Neste caso, a prática comunicativa é autêntica, com foco na comunicação, para resolução de problema.

O desenvolvimento dos conhecimentos de gramática (particularmente sintaxe), de morfologia, de fonologia/grafologia (correspondência), e de vocabulário da LE alvo podem ser um dos objetivos de jogos. Isso resulta no desenvolvimento do conhecimento organizacional, em benefícios para a habilidade linguística e competência comunicativa.

Assim, jogos podem contribuir para o desenvolvimento da LE alvo, pois: promovem a competência comunicativa, criam contexto significativo de uso da língua, integram as habilidades, aumentam a motivação. E, como enfatiza Prensky (2012, p. 147), há, atualmente, o reconhecimento e a exigência da necessidade de criação de 'jogos sérios' que "devem aderir ao e comunicar o conteúdo sério também". Desta forma, segundo o autor, o uso de jogos permite sabedoria digital, com a criação de bons jogos e seu uso adequado, para serem mais eficazes. 


\section{Livros Digitais}

Livros digitais (ou ebooks) podem ser considerados a versão eletrônica de um livro impresso ou uma edição concebida e produzida para a forma eletrônica. A versão eletrônica de um livro impresso não é, no entanto, o que destaca o livro digital. A tecnologia atualmente disponível permite que o livro digital, concebido como digital, tenha características peculiares, como portabilidade, versatilidade e interatividade. A portabilidade permite que muitos documentos sejam arquivados em um só aparelho, leve e portátil. A versatilidade possibilita sua atualização, a visualização rápida de todo o conteúdo, como também a presença de animações dinâmicas e interativas. A interatividade, característica mais importante do livro digital, agrega vários recursos, como a possibilidade de: a) alterar as cores das fontes e do fundo; b) alterar o tamanho das fontes; c) agregar som, incluindo orientações e instruções; d) criar links e hiperlinks para acessar outros aplicativos ou arquivos, como de filme e videoclipes; e) marcar trechos importantes; e f) fazer anotações.

Há muitos benefícios do uso do livro digital. Considerando o programa usado, há a possibilidade de, apenas com o uso de seus recursos, em particular em telas sensíveis ao toque, buscar definições, sinônimos ou mesmo traduções de palavras desconhecidas com simples toque, como também gravá-los.

Os livros digitais podem ter conteúdos específicos, por exemplo, sobre o próprio processo de aquisição de LE, e conteúdos gerais, sobre ecologia, saúde e podem ser de diferentes gêneros textuais, por exemplo, textos literários como histórias, histórias em quadrinhos, romances, contos, publicados como livro digital. Desta forma, o aprendiz terá material autêntico para ser usado como fonte de insumo linguístico, que deve ser escolhido adequadamente. 
Além do desenvolvimento da habilidade receptiva de leitura, aprendizes podem também desenvolver a habilidade produtiva de expressão escrita. Assim, como tarefa, livros digitais podem ser produzidos na LE alvo, em um processo de colaboração que, por sua vez, pode também ser na LE alvo, com uso autêntico da língua e negociação de significados.

\section{Vídeo e vídeo educativo}

Vídeo se refere, atualmente, ao processamento de imagens em movimento, seja para reprodução ou para gravação, na forma digital. Assim, vídeo pode ser considerado todo o material audiovisual, com imagens em movimento.

Vídeo tem inúmeras características peculiares: traz recursos de imagens e som, possibilitando aos espectadores criar um contexto, por exemplo, lugares, processos, interlocutores e sexo, idade, linguagem corporal, aumentando a compreensão e retenção do conteúdo; pode ser desenvolvido sobre qualquer tema; é um recurso motivador para aprendizes, em particular para as gerações atuais, habituadas à era de imagens; e pode ficar à disposição e disponibilizado na Internet.

Por trabalhar diferentes formas de significação, com textos, imagens e sons, vídeo é uma combinação de letramentos, trabalhando com multiletramentos, o que pode facilitar a compreensão da informação desejada e, assim, permitir a construção do conhecimento por parte do aprendiz.

Moran (1995) acrescenta que o vídeo é "sensorial, visual, linguagem falada, linguagem musical e escrita [] linguagens que interagem superpostas, interligadas, somadas e não separadas", tendo, por isso uma força que nos atinge por todos os sentidos e de todas as maneiras, seduzindo, informando, entretendo, projetando em diferen- 
tes realidades, espaços e tempos, assim combinando "a comunicação sensorial-cinestésica, com audiovisual, a intuição com a lógica, a emoção com a razão".

$\mathrm{O}$ autor faz uma avaliação do uso de vídeo em sala de aula e aponta equívocos, indicando cinco usos inadequados: vídeo-tapa buracos, para cobrir problema inesperado; vídeo-enrolação, sem relação com o conteúdo trabalhado; vídeo-deslumbramento, com foco apenas no vídeo; vídeo-perfeição, com a expectativa de apenas conter informações precisas; só-vídeo, sem sua integração ao assunto da aula.

$\mathrm{O}$ autor, ao mesmo tempo, propõe formas adequadas de utilização, que incluem vídeo como: a) sensibilização, para introduzir e despertar curiosidade sobre novo assunto; b) ilustração, com exemplos; c) simulação, com simulações da realidade; d) conteúdo de ensino, com informações de tema; e) produção, documentando eventos, modificando vídeos prontos, permitindo novas expressões de alunos; f) avaliação, dos envolvidos; g) espelho, para registro e análise de alunos; e h) integração e suporte; com integração de outras mídias.

Considerando a abordagem por conteúdo/temas para ensino/ aprendizagem de LE, qualquer vídeo escolhido quanto ao assunto pode ser usado como material didático, sobre temas variados, com o insumo linguístico necessário e adequado, auxiliando no desenvolvimento da habilidade de compreensão oral (e da compreensão escrita e de sua correspondência com a oral, com o uso de legendas ou closed

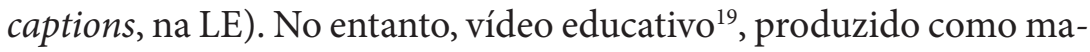
terial didático originalmente, pode ser o mais indicado para a prática docente, já que tem seu planejamento para este $f^{20}{ }^{20}$. Em qualquer dos casos, atividades podem ser criadas para acompanhamento.

Vídeo pode também ser usado como produção, tornando o aprendiz mais ativo e participativo. Neste caso, sua produção passa a 
ser uma tarefa. Para isso, idealmente, não somente o vídeo seria produzido na LE alvo, mas também a língua de comunicação para sua execução, especialmente considerando a característica de ser processo colaborativo de execução, com diferentes pessoas e seus conhecimentos diversos a serem compartilhados, neste caso, na LE alvo. Durante o processo de produção, há sempre a oportunidade de, também na LE alvo, pesquisas sobre o tema, como também de recebimento de comentários na forma de feedback, dos membros da equipe, permitindo avançar no processo de desenvolvimento da LE alvo.

Vídeo pode ser produzido por qualquer câmera de vídeo, seja filmadora ou mesmo celulares. Seu uso, em particular para as gerações de nativos digitais, pode sempre motivar. Ser produtor pode acrescentar a dimensão de autoria para aprendizes, que deixam de ter o papel somente receptivo. Para a produção do vídeo, aprendizes podem fazer pesquisas e produzir roteiros, com base em temas escolhidos. Após sua produção, o arquivo pode ser publicado na internet, o que permite comentários na forma de feedback de um público externo aos membros da equipe, aumentando os olhares ao vídeo produzido e auxiliando o avanço da LE alvo.

\section{Recursos da Web 2.0}

A Web 2.0 permite a criação e disponibilização de recursos com maior interação e colaboração entre os usuários, e maior participação ativa de cada um, como autores, acessando os ambientes, e principalmente alterando-os, editando-os e publicando conteúdos de forma a socializá-los. Assim, os usuários podem expressar-se, opinar, buscar e receber informações, colaborar no desenvolvimento de conhecimento, compartilhar conteúdos, tendo um papel mais ativo na produção e difusão da informação. 
Embora não tenham sido criados para fins pedagógicos, os recursos da Web 2.0 podem ser ferramentas eficazes como auxílio para a aprendizagem, especialmente porque permitem a participação ativa de aprendizes, com suas contribuições nos recursos criados, ou mesmo com a criação de seus próprios recursos. Em geral, os recursos permitem: a) criação de espaços em que há disponibilização de informações, com acesso por interesse; e b) maior participação em atividades de elaboração de material, com disponibilização e comentários.

Especificamente para desenvolvimento de uma LE, eles permitem interação de alguma forma (síncrona ou assíncrona), que tem sido considerada fundamental no processo de aquisição de LE, em que o aprendiz nota lacunas em seu conhecimento e busca estratégias de comunicação como também busca o conhecimento para preencher a lacuna notada. Além disso, possibilita a presença de feedback, muitas vezes na forma de comentários, de feedback explícito, com correção do uso incorreto, de feedback implícito, com a demonstração de falta de entendimento, como silêncio, pedidos de esclarecimento, recasts, importantes no processo de desenvolvimento de uma LE.

Exemplos de recursos da Web 2.0 que podem ser utilizados para o processo de ensino/aprendizagem de uma LE são: redes sociais, blogs, wikis, e podcasts.

As redes sociais têm o objetivo de socialização, o qual, por si só, implica o uso de várias formas de comunicação e expressão, incluindo o uso de línguas. As redes sociais têm a característica de possibilitar a disponibilização de informações gerais e pessoais, assim como a interação entre usuários, em particular via canais de bate-papo (chats), criando um ambiente propício a trocas de informações e construção de conhecimento. 
As redes sociais podem permitir a criação de grupos específicos, com moderação para o acesso de participantes, se transformando em ambientes virtuais de ensino e aprendizagem (AVEA), ou mesmo redes de aprendizagem, das quais participam pessoas com o mesmo objetivo, com a disponibilização de toda a informação relevante para o grupo, como material de trabalho, links e calendários de tarefas.

Elas permitem a formação de comunidades a partir de acesso moderado por parte do usuário, que pode convidar participantes (adicionar amigos) e também aceitar (ou não) convites de outros participantes. Para aprendizagem de LE, usuários que farão parte da comunidade criada podem ser estrangeiros, falantes da língua-alvo de interesse. Assim, o usuário/aprendiz estará exposto às informações disponibilizadas por todos os seus amigos (virtuais) na língua-alvo, como também poderá estabelecer interações com cada um deles. Desta forma, ele tem a oportunidade de fazer uso autêntico da língua-alvo, aproveitando os recursos de cada rede social e aprimorando sua compreensão oral e escrita, e produção oral e escrita.

Blogs são páginas disponibilizadas na Internet, cujos autores publicam conteúdos de sua escolha (informações, notícias, fotos, links, etc) para conhecimento público e aceitam comentários de participantes, de forma moderada, isto é, participantes membros de uma lista que ele convide ou autorize a postagem de mensagens. Eles têm a característica de permitir pouco espaço para respostas e diálogos, fazendo a interação ser rápida e eficiente, que ficam organizados de forma cronológica reversa, sendo o mais atual como o primeiro, sempre acompanhados da identificação do autor, da data e do horário da postagem.

Sendo páginas de fácil criação e manuseio, que permitem postagens de conteúdos e de mensagens em constante atualização, com espaços para resposta e diálogo, eles podem ser usados para comu- 
nicação entre professores e alunos, com vídeos, sugestões, recomendações, atividades, tarefas, comentários gerais, de conteúdo e de incentivo aos alunos. E podem conter informações sobre o processo de aprendizagem de uma LE, com sugestões, recomendações, etc.

Podem, também, ser espaços de interação com falantes mais proficientes, mais conhecedores da língua-alvo, assim auxiliando diretamente o processo de aprendizagem de uma LE. Consultas a blogs existentes na língua-alvo auxiliam no desenvolvimento da compreensão escrita, ao passo que a produção de blogs na língua-alvo auxilia no desenvolvimento da produção escrita.

Como tarefa, aprendizes podem criar seus próprios blogs, que se tornam seus meios de comunicação com suas reflexões na língua-alvo, que podem ganhar a dimensão de publicação, com os respectivos comentários de participante, permitindo um processo de reflexão e elaboração benéfico para o processo de conhecimento. Assim, aprendizes podem ganhar voz no processo de aprendizagem.

Wikis são recursos para escrita colaborativa, permitindo que pessoas participem do desenvolvimento do texto escrito, disponibilizado em navegadores da Internet, adicionando, modificando, excluindo conteúdos de forma colaborativa. Como não há um responsável, a estrutura do texto escrito acontece a partir das colaborações, características e necessidades dos participantes.

Com a característica de permitir a escrita colaborativa, desenvolvida de forma compartilhada entre usuários/autores, os wikis envolvem o aprendiz na própria construção do conhecimento durante a produção compartilhada, e engaja o autor/aprendiz em diálogo com os outros, com comentários durante a execução da produção do texto, permitindo a visualização de sua evolução.

Os wikis permitem o desenvolvimento das habilidades escritas na LE - compreensão e produção. Neste caso, os wikis envolvem 
produção coletiva dos textos, com aprendizes com maior e menor conhecimento da língua alvo, como também do tema sendo desenvolvido. Com essa diferente contribuição, todos os envolvidos têm ganhos cognitivos. Além disso, wikis permitem o desenvolvimento do conhecimento de gêneros textuais como resumos, resenhas, ensaios, textos jornalísticos, etc. Temas podem ser pesquisados, envolvendo a compreensão da língua-alvo, e uma tarefa de escrita colaborativa ser desenvolvida sobre o tema escolhido, no gênero definido.

Podcasts referem-se a arquivos de áudio digital, criados por qualquer pessoa, usando programas de gravação de áudio e microfone, com objetivos específicos, disponibilizado na Internet, tradicionalmente produzidos de uma forma semelhante àquela usada por locutores de rádio.

Eles podem ser usados para o processo ensino/aprendizagem de LE, uma vez que estão disponibilizados na Internet em várias línguas. Por se constituírem material de áudio autêntico, passam a ser recurso eficaz para a compreensão da língua-alvo falada por nativos (com seus diferentes sotaques e pronúncias), permitindo aumentar a amplitude de reconhecimento dos sons da língua e, assim, desenvolvendo a compreensão oral de aprendizes.

Além da compreensão oral, a produção oral pode ser desenvolvida, à medida que os aprendizes podem criar e publicar seus próprios podcasts, como uma tarefa. Esse processo de produção requer não somente planejamento técnico, mas principalmente planejamento linguístico, com preparação do conteúdo a ser gravado, envolvendo todas as habilidades, isto é compreensão oral e escrita e produção oral e escrita. Requer, também, muita pesquisa sobre os conteúdos escolhidos, permitindo a aprendizagem sobre o tema. A disponibilização do podcast na Internet permite o acesso a vários usuários, 
externos à equipe de produção, que podem dar feedback sobre seu conteúdo, também na língua-alvo.

Em suma, os vários recursos digitais podem contar com, ou desenvolver, aspectos distintos e complementares envolvidos no ensino/aprendizagem de uma LE.

\section{Considerações finais}

Há muitos recursos digitais disponíveis, atualmente. Neste artigo, apresento alguns que podem ser usados para o desenvolvimento de uma LE, a saber, áudio livros, e-pals, infográficos, jogos eletrônicos, livros digitais, vídeos, e os recursos da Web 2.0. Apresento, também, uma reflexão sobre como os recursos podem contribuir para este desenvolvimento, considerando quatro aspectos presentes na literatura sobre ensino/aprendizagem de inglês como LE: componentes da habilidade linguística, interação; integração das quatro habilidades, e motivação.

Considerando os componentes, todos os recursos, de uma forma ou outra, possibilitam seu desenvolvimento. As atividades digitais, por exemplo, têm foco nesse desenvolvimento, enquanto os outros recursos digitais apresentam o insumo linguístico, de forma contextualizada. Considerando a interação, os recursos possibilitam interação com conteúdo e interação com um falante mais proficiente na LE, permitindo negociação de significados, levantamento de hipóteses e atenção focada para o uso da língua, como também feedback avaliativo, assim criando a condição adequada para o desenvolvimento da LE. Considerando a integração das habilidades, com a abordagem por tarefas e abordagem por conteúdo, os recursos permitem o uso da língua entre aprendizes e também o uso para pesquisas sobre temas, envolvendo o desenvolvimento das habilida- 
des na LE. Considerando motivação, recursos digitais como jogos eletrônicos, vídeos, têm permitido motivação intrínseca nas várias gerações e, atualmente, na geração de nativos digitais, permitindo multimodalidades bem como iniciativa e participação, especialmente nos casos em que aprendizes são autores; recursos digitais como atividades digitais, áudio livros, livros digitais têm permitido a motivação instrumental; e recursos digitais como redes sociais, blogs, a motivação integrativa.

O desenvolvimento de uma LE, assim, conta com uma grande variedade de recursos digitais, usados por professores e alunos, ou aprendizes autônomos, fazendo da atual uma época propícia para esse desenvolvimento.

\section{Notas}

1. Embora eu considere diferenças entre as características do processo de aprendizagem de uma segunda língua e de uma língua estrangeira, especialmente no tocante à quantidade e à qualidade de exposição à língua, e os processos de memorização decorrentes, não farei, neste artigo, distinção entre eles no que se refere ao uso de fontes de referência.

2. Recurso digital, neste artigo, refere-se a recursos informatizados, cujo uso é baseado em computador.

3. Em seu artigo intitulado Interaction and second language acquisition: an ecological perspective, Paiva apresenta uma discussão sobre interação e aquisição de segunda língua. Disponível em http://www.veramenezes. com/interactionvera.pdf.

4. Há um longo debate sobre o uso de estratégias de aprendizagem em língua estrangeira, principalmente a partir de Oxford (1990).

5. Para uma explicação sobre feedback avaliativo, ver Paiva (2003).

6. Recast é uma forma de correção implícita em que um interlocutor percebe um erro e devolve para o outro a forma correta.

7. O programa hotpotatoes possibilita a criação dessas atividades. É um programa gratuito, disponibilizado em http://hotpot.uvic.ca. 
234 Celso Tumolo, Recursos digitais e aprendizagem de inglês...

8. Há diferentes níveis de compreensão que podem ser avaliados. Ver Vargas (2012) e Tumolo (2005).

9. O programa hotpotatoes possibilita a criação dessas atividades (http:// hotpot.uvic.ca).

10. Pen Pal World (http://www.penpalworld.com/) e ePals (http://www. epals.com).

11. My Language Exchange (http://www.mylanguageexchange.com) e Language for Exchange (http://www.languageforexchange.com/) e Live Mocha (http://www.livemocha.com/).

12. Veja exemplo sobre o censo do Brasil na área da saúde: http:// guiadoestudante.abril.com.br/multimidia/info-censo/pdfs/censobrasil-saude.pdf.

13. Veja exemplo prevenção: http://veja.abril.com.br/multimidia/ infograficos/evite-se-tornar-um-alvo-facil-dentro-de-sua-propria-casa.

14. Veja exemplo sobre Redes Sociais: http://www.youtube.com/ watch?v=Ah9EMonsfB0\&hd=1.

15. Sobre competência comunicativa multimodal, ver Nascimento; Bezerra; Heberle ( 2011) e Heberle (em preparação).

16. Ver exemplos de infográficos: Estruturas paralelas para escrita: http:// pinterest.com/pin/129830401728212424/, Regras de adjetivos: http:// pinterest.com/pin/129830401728212416/, Gerúndio: http://pinterest. com/pin/129830401729085878/.

17. Há uma grande discussão sobre o uso de jogos para além de entretenimento, para fins educativos, por exemplo. Na discussão, temse usado a frase jogos sérios (serious games em inglês).

18. Ver Ontoria, de Luque, e Gomes (2008).

19. Gomes (2008) apresenta uma reflexão sobre o uso de vídeo educativo e critérios para avaliação.

20. Vídeos produzidos para ensino/aprendizagem de LE podem ser encontrados na Internet: http://www.learnerstv.com/Free-Languagevideo-lecture-courses.htm, http://www.learnerstv.com/Free-LanguageVideo-lectures-ltv201-Page1.htm , e http://www.englishmedialab.com/ vocabulary.html. 


\section{Referências}

AMARAL, L. Revisiting current paradigms in computer assisted language learning research and development. Itha do Desterro, 60, p. 365-389. Florianópolis, SC. 2011.

BACHMAN, L. Fundamental considerations in language testing. Oxford, UK: Oxford University Press. 1990.

BACHMAN, L.; PALMER, A. Language testing in practice. Oxford, UK: Oxford University Press, 1996.

GARDNER, R. C. Social Psychology and second language learning: The role of attitudes and motivation. London, GB: Edward Arnold. 1985. Disponível em http://publish.uwo.ca/ gardner/ .

. Integrative motivation and second language acquisition. Canadian Association of Applied Linguistics/Canadian Linguistics Association Joint Plenary Talk - May 30, 2005, London, Canada. Disponível em http:// publish.uwo.ca/ gardner/.

GEE, J. P. Good Video Games and Good Learning, 2005. Disponível em http://www.jamespaulgee.com/sites/default/files/pub/GoodVideo GamesLearning.pdf.

GOMES, L. F. Vídeos didáticos: uma proposta de critérios para análise. 2008. Disponível em http://emaberto.inep.gov.br/index.php/RBEP/ article/viewFile/684/1153.

HEBERLE, V. Estudos em multiletramentos e possíveis intersecções com o ensino de inglês no Brasil. Em preparação.

KRASHEN, S. D. Second language acquisition and second language learning. Oxford: Pergamon. 1981.

. Principles and practice in second language acquisition. Oxford, Pergamon. 1982.

LANLOW, J.; RITCHIE, J.; CROOKS, R. Infographics: The power of visual story telling. Hoboken, New Jersey: John Wiley \& Sons, Inc. 2012.

LONG, M. H. Input and second language acquisition theory. In: GASS, S. M.; MADDEN, C. G. (Orgs.). Input in second language acquisition. Rowley, MA: Newbury House. 1985, p. 377-393. 
. The role of linguistic environment in second language acquisition. In: RITCHIE, C.; BHATIA, T. K. (Orgs.). Handbook of second language acquisition. New York: Academic Press, 1996. p. 413-468.

MORAN, J. M. O Vídeo na Sala de Aula. Comunicação \& Educação. São Paulo, ECA-Ed. Moderna, v. 2, p. 27-35, jan/abr 1995. Disponível em http://www.eca.usp.br/moran/vidsal.htm.

NASCIMENTO, R. G.; BEZERRA, F. A. S.; HEBERLE, V. M. Multiletramentos: iniciação à análise de imagens. Linguagem \& Ensino, v. 14, n. 2, p. 529-552, jul/dez. 2011.

ONTORIA, A.; de LUQUE, A.; GOMES, J. P. R. Aprender com Mapas Mentais: uma estratégia para pensar e estudar. São Paulo: Madras, 2008.

OXFORD, R. Language learning strategies: What every teacher should know. Boston, MA: Heinle \& Heinle. 1990.

. Integrated Skills in the ESL/EFL Classroom. Eric Digest. 2001. Disponível em http://eric.ed.gov/?id=ED456670 e http://files.eric. ed.gov/fulltext/ED456670.pdf .

PAIVA, V. L. M. O. Feedback em ambiente virtual. In: LEFFA, V. (Org.). Interação na aprendizagem de línguas. Pelotas: Educat, 2003, p. 219-254. Disponível em http://www.veramenezes.com/feedback.htm .

. Interaction and second language acquisition: an ecological perspective. Disponível em http://www.veramenezes.com/interactionvera.pdf .

PRENSKY, M. Digital Natives, Digital Immigrants: do they think differently. 2001. Disponível em http://marcprensky.com/articles-in-publications/.

. The motivation of gameplay. 2002. Disponível em http:// marcprensky.com/articles-in-publications/.

. Brain gain: technology and the quest for digital wisdom. New Youk: NY, Palgrave MacMillan. 2012.

RYAN, R.; DELCI, E. Intrinsic and Extrinsic Motivations: Classic Definitions and New Directions. Contemporary Educational Psychology v. 25, p. 5467, 2000. Disponível em http://www.sciencedirect.com/science/article/ pii/S0361476X99910202.

SCHMIDT, R. The role of consciousness in second language learning. Applied Linguistics 11, 1990, p. 206-226. 
. Consciousness and foreign language learning. A tutorial on the role of attention and awareness in learning. In: SCHMIDT, R. (Org.). Attention and awareness in foreign language learning. Honolulu: University of Hawaii Press, 1995, p. 1-63.

SWAIN, M. Communicative competence: Some roles of comprehensible input and comprehensible output in its development. In: S. GASS; C. MADDEN. (orgs.). Input in second language acquisition. Rowley, MA: Newbury House. 1985, p. 235-256.

TUMOLO, C. H. S. Assessment of reading in English as a foreign language: Investigating the defensibility of test items. Tese de Doutorado defendida no Programa de Pós-graduação em Inglês - PPGI, Universidade Federal de Santa Catarina - UFSC. 2005. Disponível em http://www.tede.ufsc. br/teses/PLLE0315.pdf

VARGAS, D. S. O plano inferencial em atividades escolares de leitura: o livro didático em questão. Revista Intercâmbio, São Paulo: LAEL/ PUCSP, v. XXV, p. 126-152, 2012. Disponível em http://revistas.pucsp. br/index.php/intercambio/article/view/10137/7617.

\section{Bibliografia Complementar}

ABRALE. Uso do Facebook em educação. 13/08/2013. Disponível em http:// www.abrale.com.br/?p=3545.

Canal de Ensino. 50 razões para usar o Facebook em sala de aula. Disponível em http://canaldoensino.com.br/blog/50-razoes-para-usar-o-facebookem-sua-sala-de-aula.

CARITÁ, E. C.; PADOVAN, V. T.; SANCHES, L. M. P. Uso das Redes Sociais no Processo de Ensino Aprendizagem. 2011. Disponível em http://www. abed.org.br/congresso2011/cd/61.pdf.

DUFFY, P.; BRUNS, A. The Use of Blogs, Wikis and RSS in Education: A conversation of possibilities. In: Proceedings Online Learning and Teaching Conference. Brisbane, 2006, p. 31-38. Disponível em http:// eprints.qut.edu.au/5398/1/5398.pdf.

PAIVA, V. L. M. O. O Uso de Tecnologias em Aulas de LE. Disponível em http://www.veramenezes.com/paivabohn.pdf. 
PARKER K. R.; CHAO, J. T. Wiki as a Teaching Tool. Interdisciplinary Journal of Knowledge and Learning Objects, v. 3, 2007. Disponível em http://www.ijklo.org/Volume3/IJKLOv3p057-072Parker284.pdf.

SORENSEN, B. H.; MEYER, B. Serious Games in language learning and teaching: a theoretical perspective. Situated Play, Proceedings of DiGRA 2007 Conference. Disponível em http://www.digra.org/wp-content/ uploads/digital-library/07312.23426.pdf.

SUPER INTERESSANTE. 2013: o ano do livro digital. Disponível em http://super.abril.com.br/cultura/2013-ano-livro-digital-740039.shtml.

WEISSHEIMER, J.; BERGSLEITHNER, J. M.; LEANDRO, D. C. Escrita Colaborativa com Google Docs na aprendizagem de Inglês como Língua Adicional. Disponível em http://www.abrapui.org/anais/Comunicacoes CoordenadasLingua/8.pdf.

(Recebido em 21/03/14. Aceito em 21/05/14) 